Prepared in cooperation with the

Southwest Florida Water Management District

\title{
Numerical Simulation of Aquifer Tests, West-Central Florida
}
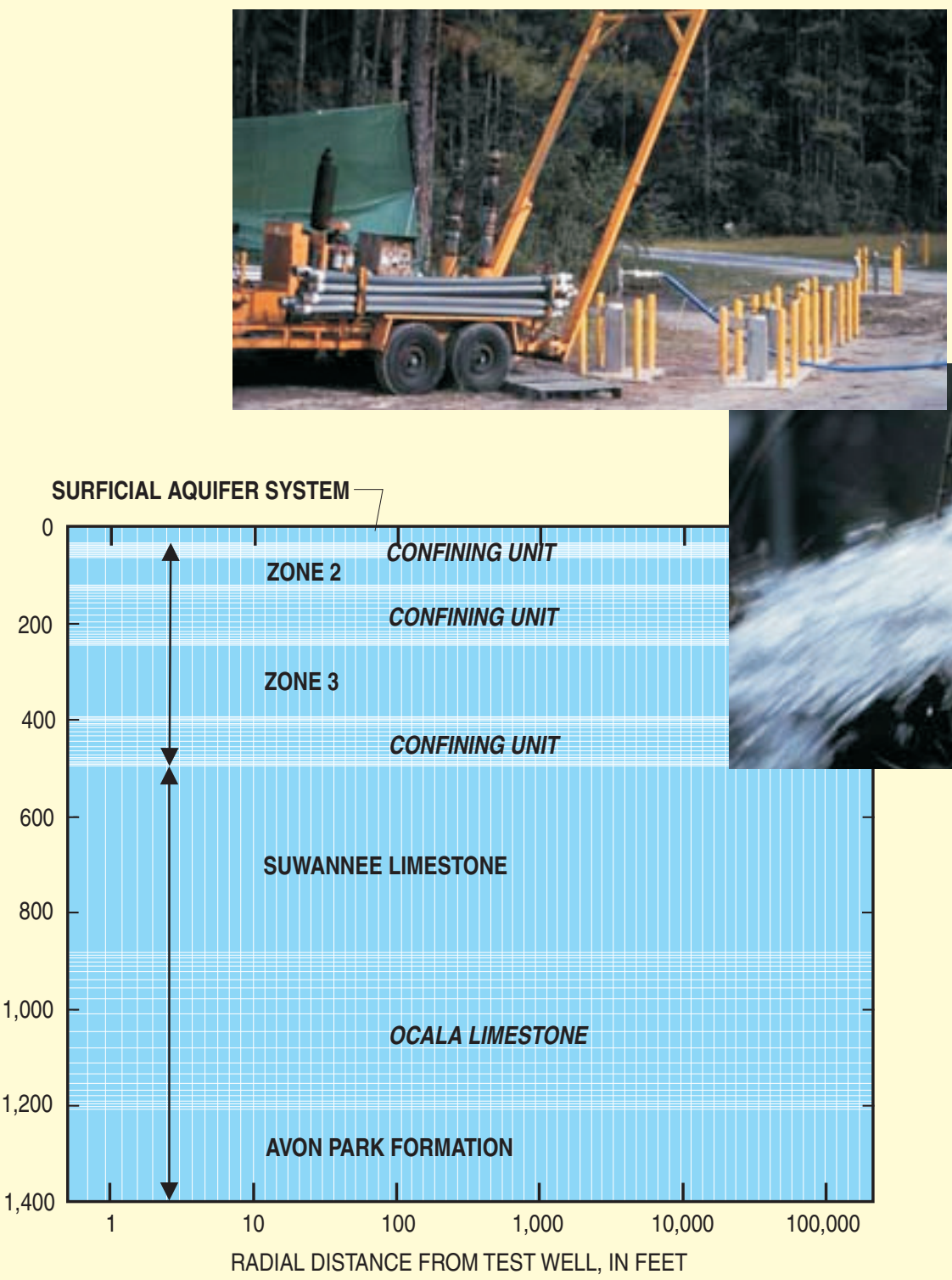

Scientific Investigations Report 2005-5201

U.S. Department of the Interior

U.S. Geological Survey 